REVISTA DE GESTAOOE SECRETARRADO

MANAGEMENT AND AdMINISTRATIVE

PROFESSIONAL REVIEW

ISSN: 2178-9010
Revista GeSec

São Paulo, SP, Brasil

v. 12 , n. 1, p. 308-331

jan. /abr. 2021

DOI: http://dx.doi.org/10.7769/gesec.v12i1.1178

\title{
De repente professor: uma análise sobre a dupla jornada dos Secretários Executivos atuando como docentes
}

\section{Suddenly professor: an analysis about a double workday of Executive}

\section{Secretaries acting as professors}

\author{
Juliene do Socorro Cardoso Rodrigues ${ }^{1}$ \\ Raul Vitor Oliveira Paes ${ }^{2}$ \\ Wheeler Wallace Levy Sinézio Costa ${ }^{3}$
}

\section{Resumo}

Para o profissional de secretariado, a docência tem emergido enquanto novo desafio. Considerando essa discussão, o presente trabalho objetivou analisar os benefícios, as dificuldades, semelhanças e diferenças da atuação paralela como secretário executivo (SE) e docente. O referencial teórico foi baseado nas temáticas sobre dupla jornada e trabalho docente, as vertentes de atuação do profissional de secretariado executivo contemporâneo, além de reflexões sobre a figura dos secretários-docentes. O estudo é de cunho exploratório e descritivo, com abordagem qualitativa e técnica de análise de conteúdo. A coleta de dados foi realizada por meio de questionário enviado a 11 (onze) profissionais de secretariado que atuam ou já atuaram em dupla jornada. Os resultados evidenciam que os principais benefícios são: intercâmbio de conhecimento, ampliação da rede de relacionamentos, atualização constante e transmissão de experiências profissionais. Entre as dificuldades estão a falta de tempo, desgaste psicológico, cansaço e acúmulo de funções. Quanto às semelhanças identificadas estão responsabilidade, comprometimento, gestão da informação e de pessoas, gestão do tempo e relacionamento interpessoal. As principais diferenças entre as duas atuações residem na flexibilidade da atuação docente e maior autonomia na docência.

Palavras-chaves: Docência. Secretariado. Jornada de trabalho.

\footnotetext{
${ }^{1}$ Doutoranda do Programa de Pós-graduação em Letras da Universidade Federal do Pará (UFPA), Secretária Executiva na UFPA.

${ }^{2}$ Mestre em Gestão Pública, Docente na Universidade do Estado do Pará (UEPA), Secretário Executivo na UFPA.

${ }^{3}$ Graduando em Secretariado Executivo na UEPA.
} 


\section{Abstract}

For a secretarial professional, the teaching emerges while a new challenge. Considering this discussion, this article aimed to analyze the benefits, difficulties, similarities, and differences of parallel acting as executive secretary (ES) and professor. The theoretical approach was based in themes about a double workday and teaching work, the strands of professional acting of contemporary executive secretary, besides reflections about the secretaries-professors figure. The study is an exploratory nature and descriptive, with qualitative approach and technique of content analysis. The data collect was realized through a questionnaire sent 11 (eleven) secretariat professionals which act or already acted in double workday. The results evidence that principal benefits are a knowledge exchange, enlargement of relationship network, constant update, and transmission of professional experiences. Among the difficulties they are a time lack, psychological wear, tiredness, and role accumulation. As the similarities identified they are responsibility, commitment, information and people management, time management, and interpersonal relationship. The principal differences between two actions resides in flexibility of teaching acting and more autonomy in teaching.

Keywords: Teaching. Secretariat. Work hours.

\section{Introdução}

Como iniciar uma pesquisa sobre docência sem mencionar que o processo de ensinoaprendizagem é uma tarefa árdua. Parece uma conclusão óbvia, porém necessária, porque ensinar é a ponta de um novelo complexo, tendo como cenário a sala de aula. São muitos os processos envolvidos na docência e inúmeros os desafios para o profissional que decide fazer parte desse enredo (Freire, 2003).

Para quem escolheu a docência, muito além do que simplesmente uma profissão ou salário (que não é dos melhores) e amor, é a consciência de que um professor que deixa marcas deve se comunicar, inspirar e transformar vidas (Rasmussen, 2015).

Mudar a vida das pessoas para melhor é que o se almeja, mesmo que a falta de tempo suficiente para planejamento didático, estudo, pesquisa, orientação, sejam algumas das dificuldades encontradas no dia a dia.

Se o processo de ensino e aprendizagem já é uma tarefa árdua para um profissional da área da educação, o qual passa durante a graduação por uma formação com disciplinas voltadas para a licenciatura, para um Secretário Executivo (SE), com formação em Bacharelado, torna-se mais difícil ainda. Isso porque, durante sua formação acadêmica, ele 
geralmente não cursa disciplinas como: didática, metodologias, práticas de ensino e aprendizagem, teoria e práticas pedagógicas (planejamento escolar), psicologia e filosofia da educação.

Essa formação para a docência dos cursos de licenciatura é um fator que influencia sobremaneira na atuação em sala de aula, apesar de não ser determinante para um bom desempenho na docência, pois em qualquer área de conhecimentos existem os bons e os maus profissionais (Oliveira \& Silva, 2012).

No entanto, mesmo sem uma formação específica para a atuação como docente, alguns secretários executivos já vêm atuando em sala de aula. Essa dupla experiência pode colaborar para que a prática seja contextualizada em outra. É o que preceitua a Base Nacional Comum Curricular (BNCC), atualmente uma nova referência para a educação nacional, que apresenta como competências gerais:

- A contextualização sociocultural das ciências e da tecnologia deve ser vista como uma competência geral, que transcende o domínio específico de cada uma das ciências [...];

- Valorizar a diversidade de saberes e vivências culturais e apropriar-se de conhecimentos e experiências que lhe possibilitem entender as relações próprias do mundo do trabalho [...];

- Argumentar com base em fatos, dados e informações confiáveis, para formular, negociar e defender ideias, pontos de vista e decisões [...] (Brasil, 2017, p. 9).

Mas o conhecimento prático como secretário executivo nem sempre é o suficiente para uma atuação docente. Essa inquietação deu origem à questão deste artigo: Quais os desafios da dupla jornada do Secretário Executivo atuando como docente?

O interesse pela pesquisa, como já anunciado acima, decorre do fato de que a formação acadêmica qualifica o profissional com um perfil para exercer atividades técnicas, operacionais, estratégicas e de assessoria, mas, quando ele se depara com a oportunidade de atuar na docência, encontra muitos desafios (Faria \& Reis, 2008). Tais dificuldades, de acordo com Oliveira \& Silva (2012), podem ser vencidas quando o profissional (SE/docente) enfrenta as incertezas e inseguranças buscando novas competências e habilidades, em um processo de formação continuada.

Por outro lado, reforça-se a justificativa desta pesquisa em razão dos poucos estudos embrionários sobre a temática, mas que, em sua maioria, são exploratórios, e que, no geral, possuem o objetivo de investigar a atuação do profissional de SE enquanto docente (como dedicação exclusiva) ou de vislumbrar a carreira docente para o profissional com competência técnica. Nessa perspectiva, estudar acerca da dupla jornada de trabalho como SE e docente pode auxiliar a compreender melhor a atuação do profissional na docência, bem como indicar possibilidades de desenvolvimento. 
A contribuição deste estudo para a comunidade acadêmica consiste na evidenciação de um retrato dos profissionais que atuam em dupla jornada, como secretário executivo e docente, bem como os impactos, benefícios e desdobramentos de tal atuação na vida profissional e pessoal dos sujeitos. Nesse viés, tecemos como objetivo geral: Investigar os desafios e benefícios da dupla jornada como secretário executivo (SE) e docente; como objetivos específicos: a) mapear o perfil dos secretários-docentes que buscaram qualificação para atuar como docentes; b) apontar as atitudes profissionais incomuns existentes na atuação como secretário executivo e docente.

O presente estudo é composto das seguintes seções, incluindo esta introdução. Após, apresentamos o referencial teórico, que inclui os tópicos de mercado de trabalho e o profissional de secretariado, formação específica do profissional e secretários executivos docentes. Posteriormente, prossegue-se com a descrição dos procedimentos metodológicos e com a análise e discussão dos resultados. Por fim, finaliza-se com as considerações finais e as referências utilizadas no trabalho.

\section{Referencial Teórico}

O referencial teórico usado para este trabalho compreende os tópicos relacionados à dupla jornada e trabalho docente, vertentes de atuação do profissional de secretariado executivo contemporâneo, a figura dos secretários-docentes e o ensino contextualizado. Tal abordagem com vistas a um embasamento teórico consistente à discussão em voga.

\subsection{Trabalho docente no contexto acadêmico-universitário: dupla jornada e seus desdobramentos}

A formação de profissionais em diversas áreas do conhecimento, formalmente realizada por cursos técnicos e de graduação, é amparada pela Lei de Diretrizes e Bases da Educação Nacional (LDB), que possui alguns princípios, dentre eles o do ensino contextualizado, ou seja, aquele que leva em consideração os saberes e práticas específicas de cada área de formação (Brasil, 1996). Nesse contexto, insere-se o docente, figura responsável pelo gerenciamento da facilitação do conhecimento aos estudantes.

Falar em docência é viajar em maré alta e agitada, pois a educação é um processo de constante criação de conhecimento, transformação/reinvenção de vidas e realidades. Isso a partir da ação-reflexão humana (Freire, 2003). 
No contexto acadêmico-universitário, a educação requer um olhar cuidadoso, pois é preciso capacitar/qualificar adequadamente os professores, mesmo que muitas vezes as universidades apresentem condições de trabalho incompatíveis com a formação necessária (Chauí, 2003).

Por outro lado, importa salientar que, além do ensino necessitar refletir sobre o contexto profissional de um determinado saber, o componente didático-pedagógico é essencial nessa atuação. Porém, quando se analisa a atuação dos docentes dos cursos de graduação de um modo geral, depara-se com algumas particularidades, dentre elas: a) possuir a experiência profissional requerida, mas não a didática necessária para ministrar aulas (Nossa, 1999); b) possuir a didática, porém a experiência profissional insuficiente; e c) possuir a didática requerida, porém em área diferente a do curso que está lotado.

Desse modo, quando o docente está em exercício na sala de aula e que, por isso, demande um domínio didático-pedagógico mais consolidado, ele procura suprir essa lacuna com a realização de capacitações e aperfeiçoamentos específicos, sejam oferecidos pela própria instituição onde atua ou instituições externas (Nossa, 1999, Costa \& Porto, 2016).

Por outro lado, uma alternativa que acaba sendo uma parte da solução, tanto para os docentes que necessitam de maior didática como para os que necessitam de maior experiência profissional, é a atuação em dupla jornada, enquanto profissional da área e docente. Assim, a atuação em dupla jornada ocorre entre a atuação profissional específica da área em um turno e a atuação docente em outro turno, sendo docente em tempo parcial (Nossa, 1999, Lima \& Lima-Filho, 2009). Desse modo, o profissional possui duas cargas-horárias de trabalho e duas diferenças de atuação profissional. Quanto a isso, um contraponto importante a mencionar, com base no estudo qualitativo de Bartlett (2004), é que essa atuação, frequentemente, ocasiona uma carga horária extra além da contratada, que resulta na sobrecarga de atividades docentes que não são financeiramente remuneradas.

Em se tratando de aspectos quantitativos, Aili e Brante (2007) trazem contribuições a respeito do tempo dedicado à qualificação profissional do trabalho docente, após análises exaustivas de 1166 relatórios de 59 professores suecos. As principais conclusões atestam que o tempo de qualificação profissional não é contabilizada na carga-horária total regulamentada, o que traz reflexões acerca da composição das atividades docentes alinhadas com as regulamentações legais, incluindo as atividades de qualificação/capacitação e, com isso, aprofundando as discussões sobre a jornada docente, principalmente fora da sala de aula.

Mas as razões para a atuação em dupla jornada podem ser as mais variadas: por complementação salarial, por fatores circunstanciais de oportunidade (Nossa, 1999), bem 
como por exigências legais e institucionais, uma vez que, principalmente, nas instituições federais de ensino, há cargos que devem ser ocupados, preferencialmente ou obrigatoriamente, por docentes da carreira do magistério superior (Barbosa \& Mendonça, 2014, Campos et al., 2008), o que acaba sendo a função gerencial-administrativa também orgânica, de modo indireto, no processo de trabalho docente.

A literatura sobre dupla jornada (com atuação docente em tempo parcial) é restrita e aparece como resultado de outras variáveis de pesquisa, não sendo objeto direto de estudo. Exemplos de estudos nessa direção são a formação do corpo docente em cursos de Contabilidade no Brasil (Nossa, 1999); ou as condições de trabalho do professor universitário em uma universidade federal (Lima \& Lima-Filho, 2009), além de estudos que revelam competências para professores-gestores em universidades federais (Barbosa \& Mendonça, 2014, Campos et al., 2008), o que também indica que a atuação em dupla-jornada pode ser percebida/identificada em uma mesma instituição.

A atuação docente em tempo parcial (ou em dupla jornada), por meio dos estudos anteriormente citados, revelam algumas particularidades. Por um lado, quanto aos benefícios, há conclusões de que a atuação em dupla jornada promove um intercâmbio possível e necessário entre as atividades profissionais e acadêmicas (Winkel, Cassimiro \& Scachetti, 2015), bem como a sensação de estar atualizado quanto às mudanças mercadológicas (Nossa, 1999).

No entanto, há evidências de problemas na atuação em dupla jornada de trabalho na área específica e na docência: a) o professor corre o risco de apenas informar o estudante de como fazer e não o porquê fazer atribuições profissionais (Nossa, 1999), não contribuindo para o pensamento crítico do futuro profissional; b) relatos de condições prejudicadas de saúde física e mental por sobrecarga ocupacional de atribuições e atividades extras (Lima \& Lima-Filho, 2009), ocasionando problemas variados como Lesão por Esforço Repetitivo (LER), tendinite, dores lombares, cansaço mental, estresse, ansiedade (Campos et al., 2008, Lima \& Lima-Filho, 2009); c) exigência de alto grau de concentração e atenção na realização de tarefas (Tavares, Alves, Garbin, Silvestre \& Pacheco, 2007, Lima \& Lima-Filho, 2009), o que pode refletir na precarização e na desvalorização do trabalho docente a médio e longo prazo; d) dedicação e gestão do tempo necessárias para a realização da jornada (Campos et al., 2008).

Apesar dos desafios e problemáticas relacionados à atuação em dupla jornada no processo de trabalho técnico-docente, o recomendável é que haja docentes tanto com dedicação exclusiva, para dedicação à pesquisa e à produção de conhecimento, bem como 
com tempo parcial (em dupla jornada), para atualização e intercâmbio de conhecimentos da academia com o mercado de trabalho ou na prática profissional (Nossa, 1999, Winkel, Cassimiro \& Scachetti, 2015).

\subsection{Vertentes de atuação profissional como secretários-docentes}

No âmbito da graduação superior, os cursos de graduação em Secretariado Executivo possuem quatro áreas de atuação, preconizadas pelas Diretrizes Curriculares Nacionais (DCN) para os cursos de graduação em Secretariado Executivo (Brasil, 2005): Assessoria, Gestão, Empreendedorismo e Consultoria. No entanto, uma área de atuação que não está prevista nas DCN é a docência, embora o termo secretário-docente tenha surgido a primeira vez no Código de Ética do profissional de secretariado (Brasil, 1988). Dessa forma, o secretário executivo pode encontrar na docência uma outra oportunidade para a atuação profissional, porém com diferenciações e algumas premissas necessárias: a primeira é que devido à formação em secretariado ser voltada para as problemáticas organizacionais, então os cursos, costumeiramente, não possuem um olhar direcionado para a docência (Costa \& Porto, 2016).

Todos os conhecimentos acadêmicos e adquiridos no dia a dia de um profissional de secretariado são ferramentas essenciais para que ele possa atuar de acordo com aquilo que as instituições e a sociedade esperam (Müller, Stece \& Cegan, 2015). No entanto, além de serem multi, trans e interdisciplinares, precisam ser promotores de sua própria história. E é com esse perfil que a docência se torna uma experiência desafiadora.

Considerando que a área de SE possui estreita relação da teoria e prática com a área administrativa, o profissional possui qualificação voltada para muitas atividades operacionais; devido a esse fato, na atuação docente tem encontrado a possibilidade de demonstrar que suas capacidades vão muito além das atividades operacionais (Nossa, 1999). Porém, alguns cursos de graduação em secretariado não contemplam disciplinas ligadas ao preparo do profissional para atuar como docente (Nóbrega \& Adelino, 2013, Santiago \& Silva, 2018). Desse modo, os docentes que possuem formação específica em Secretariado e atuam em cursos de formação necessitam de reforços, capacitações e orientações pedagógicas específicas para atuação na sala de aula; orientações extras aos estudantes, e, consequentemente, melhor contextualização do ensino (Sanches, Cielo \& Yaegashi, 2018).

Costa \& Porto (2016) acreditam que são necessários conhecimentos específicos para atuação nos ensinos técnico e superior em Secretariado, com a realização de especializações próprias de magistério, didática e docência, seja nos níveis lato sensu, stricto sensu ou em cursos de aperfeiçoamento. 
Sanches, Cielo \& Yaegashi (2018), em uma análise acerca da formação didáticopedagógica dos docentes em Secretariado Executivo, informam que 91,4\% dos docentes atuantes em cursos no Brasil já cursaram alguma capacitação, para suprimento da lacuna pedagógica, sendo que os modos de capacitação mais destacados foram por meio de disciplinas em cursos de pós-graduação, de cursos proporcionados pela mesma instituição onde atua e em especialização voltada ao ensino. Costa \& Porto (2016) também encontraram resultados semelhantes, em estudo anterior. Assim, os secretários docentes procuram buscar complementações para suprir a lacuna pedagógica e, assim, poder exercer instrução e reflexões de conhecimentos específicos junto aos estudantes.

Aos profissionais que encaram essa dupla jornada outras exigências lhes são apresentadas: regulação educativa que pressupõe maior responsabilização dos trabalhadores, demanda por maior autonomia (ou heteronomia) destes, capacidade de resolver localmente os problemas encontrados em sala de aula e mesmo fora dela, reflexão sobre a sua realidade e a do aluno, trabalho coletivo, cooperativo, integrativo, prezando pelo ensino (inter, trans e multi) disciplinar, conferindo um caráter desafiador da docência ainda maior. (Ávila Assunção \& Andrade Oliveira, 2009).

Por ser uma profissão com grande sobrecarga de responsabilidades, o trabalho docente há algum tempo vem sendo tema de diversos estudos, com o intuito de incentivar a formação de grupos e de redes de pesquisadores organizados para esse fim. (Campos et al., 2008, Lima \& Lima-Filho, 2009).

Além dessas problemáticas relatadas na atuação docente em Secretariado Executivo, outros estudos buscam evidenciar a atuação secretarial na docência, formação do profissional que atua como profissional universitário, e outras discussões, como expostos no Quadro 1:

\begin{tabular}{|c|l|}
\hline Autores & \multicolumn{1}{|c|}{ Objetivo, contexto investigado e principais conclusões } \\
\hline Faria, Reis (2008) & $\begin{array}{l}\text { O presente trabalho teve como objetivo discorrer sobre os requisitos necessários } \\
\text { para que um profissional formado em Secretariado Executivo possa atuar como } \\
\text { docente. Buscou, ainda, salientar os obstáculos que tal profissional poderá } \\
\text { enfrentar para ministrar aulas e explicitar o perfil requerido para se trabalhar nesta } \\
\text { área de atuação. }\end{array}$ \\
\hline $\begin{array}{c}\text { Silva, Barros \& Sousa } \\
(2010)\end{array}$ & $\begin{array}{l}\text { Este artigo teve como objetivo geral investigar como a experiência do Secretário } \\
\text { Executivo no contexto das organizações contribui na construção da sua formação } \\
\text { docente. Para tanto, foi realizada uma pesquisa de campo com professores em } \\
\text { Secretariado Executivo através de um questionário. Os principais resultados } \\
\text { obtidos sinalizaram que a experiência do Secretário Executivo no âmbito } \\
\text { organizacional é fundamental para a construção da sua formação docente por } \\
\text { possibilitar a transmissão de conhecimentos adquiridos na prática da profissão, } \\
\text { sendo necessário o alinhamento entre a prática profissional e os conhecimentos } \\
\text { pedagógicos e didáticos. }\end{array}$ \\
\hline
\end{tabular}




\begin{tabular}{|c|c|}
\hline $\begin{array}{l}\text { Nóbrega \& Adelino } \\
\qquad(2012)\end{array}$ & $\begin{array}{l}\text { O trabalho tem como objetivo identificar as áreas em nível de mestrado e } \\
\text { doutorado nas quais os docentes com formação em secretariado têm buscado } \\
\text { ingressar. A metodologia adotada é caracterizada como bibliográfica, exploratória } \\
\text { e descritiva. Foi realizado um levantamento de dados no site do Inep e na } \\
\text { plataforma Lattes do CNPq, no período de outubro a novembro de } 2011 \text {, visando } \\
\text { quantificar os cursos de secretariado existentes no Brasil e identificar, através dos } \\
\text { currículos dos bacharéis dessa área, em quais programas de pós-graduação esses } \\
\text { estão inseridos. As pós-graduações que mais têm acolhido os bacharéis em } \\
\text { secretariado são as das áreas de administração, educação, engenharia de produção e } \\
\text { ciências da informação. }\end{array}$ \\
\hline $\begin{array}{l}\text { Barros, Silva \& Lopes } \\
\text { (2014) }\end{array}$ & $\begin{array}{l}\text { O estudo objetivou investigar a formação dos profissionais de Secretariado } \\
\text { Executivo que atuam na docência universitária. Para a coleta de dados foi utilizado } \\
\text { um questionário voltado para professores universitários que possuem graduação } \\
\text { em Secretariado Executivo, atuantes como docentes em Instituições de Ensino } \\
\text { Superior do Brasil. Após a análise dos resultados, inferiu-se que a formação desses } \\
\text { profissionais ocorre, principalmente, na graduação bacharelado a qual não tem } \\
\text { como foco a preparação para a docência. A pesquisa evidenciou a existência de } \\
\text { lacunas a serem preenchidas pelos professores bacharéis em Secretariado no que se } \\
\text { refere aos conhecimentos docentes visto que a graduação, a vivência profissional e } \\
\text { os cursos de pós-graduação são insuficientes para a construção de saberes } \\
\text { pedagógicos. }\end{array}$ \\
\hline $\begin{array}{l}\text { Barros, Silva \& Barros } \\
\text { (2016) }\end{array}$ & $\begin{array}{l}\text { O trabalho teve por objetivo investigar as contribuições da abordagem de ensino } \\
\text { com pesquisa para a cientificidade secretarial. Para tanto, foi desenvolvida uma } \\
\text { pesquisa qualitativa por meio das técnicas de pesquisa observação participante e } \\
\text { narrativa escrita. As narrativas escritas foram realizadas por } 19 \text { estudantes que } \\
\text { desenvolveram o Estágio Supervisionado, em } 2014 \text {. Inferiu-se que as contribuições } \\
\text { do ensino com pesquisa para a cientificidade secretarial ocorrem principalmente, } \\
\text { pelo fato de formar um novo perfil acadêmico e profissional por meio de uma } \\
\text { cultura científica no curso; insere o educando no processo investigativo durante a } \\
\text { realização das disciplinas estudadas ao longo de sua trajetória universitária. }\end{array}$ \\
\hline Vaz (2015) & $\begin{array}{l}\text { O objetivo geral deste estudo é compreender como as experiências pedagógicas das } \\
\text { histórias de vida contribuem para a constituição do profissional professor de } \\
\text { Secretariado Executivo. A metodologia utilizada foi a história oral de vida. A } \\
\text { coleta de dados concretizou-se através das narrativas de duas professoras do curso } \\
\text { de Secretariado Executivo da UPF. Após a análise das narrativas, compreende-se } \\
\text { que a constituição profissional das docentes de Secretariado Executivo da UPF } \\
\text { vem se realizando a partir de sua prática, por meio das experiências cotidianas de } \\
\text { atuação, na coletividade e em outros espaços por elas visualizados. }\end{array}$ \\
\hline Santiago \& Silva (2017) & $\begin{array}{l}\text { O estudo objetivou identificar as estratégias utilizadas pelos secretários-docentes } \\
\text { para ampliar a docência secretarial. O método utilizado foi a pesquisa bibliográfica } \\
\text { com abordagem qualitativa. O estudo de caso foi na Universidade Federal de } \\
\text { Pernambuco, a partir da identificação de } 5 \text { (cinco) secretários-docentes, os quais } \\
\text { são os sujeitos dessa pesquisa. Observou-se, portanto, que os secretários-docentes } \\
\text { possuem o desejo de compartilhar e enriquecer as competências de secretariado, } \\
\text { correlacionando o conteúdo das disciplinas às experiências vivenciadas entre } \\
\text { docentes e discentes, assim como formar novos profissionais de Secretariado e, } \\
\text { certamente, secretários-docentes. }\end{array}$ \\
\hline
\end{tabular}




\begin{tabular}{|c|c|}
\hline $\begin{array}{l}\text { Sanches, Cielo \& } \\
\text { Yaegashi (2018) }\end{array}$ & $\begin{array}{l}\text { O estudo possui o objetivo de compreender os desafios enfrentados pelos } \\
\text { profissionais bacharéis em secretariado executivo que atuam como docentes no } \\
\text { ensino superior nas IES públicas do Brasil. Dessa forma, a coleta de dados se deu } \\
\text { por meio de questionários aplicados aos docentes dos cursos de Secretariado das } \\
\text { IES públicas do Brasil e por meio de análises nas grades curriculares das } \\
\text { disciplinas. Como principais resultados obtidos, pode-se destacar que os } \\
\text { respondentes apontam para a necessidade de desenvolvimento de competências e } \\
\text { preparo para a atividade dos bacharéis docentes, por meio de capacitações didático- } \\
\text { pedagógicas, que auxiliem no processo de ensino-aprendizagem. }\end{array}$ \\
\hline $\begin{array}{l}\text { Cajado, Barros \& Silva } \\
\text { (2018) }\end{array}$ & $\begin{array}{l}\text { Este trabalho tem como objetivo analisar as contribuições do Programa de } \\
\text { Iniciação à Docência da Universidade Federal do Ceará para a formação em } \\
\text { secretariado executivo, na percepção de estudantes-monitores. A metodologia } \\
\text { utilizada foi uma pesquisa qualitativa e descritiva a partir de levantamento } \\
\text { bibliográfico e estudo de campo. A investigação foi desenvolvida com a } \\
\text { participação de sete estudantes do curso de secretariado executivo da Universidade. } \\
\text { As técnicas de pesquisa utilizadas para o levantamento das informações foram a } \\
\text { entrevista e o questionário. A interpretação dos dados foi feita por meio da análise } \\
\text { do conteúdo. Após a análise dos resultados inferiu-se que o programa colabora } \\
\text { para a construção de experiências acadêmicas gerando uma formação que } \\
\text { ultrapassa a sala de aula ao incentivar a emancipação intelectual, contribuir para a } \\
\text { produção da pesquisa secretarial e desenvolver conhecimentos básicos necessários } \\
\text { à docência na educação superior. }\end{array}$ \\
\hline $\begin{array}{l}\text { Miranda \& Tonieto } \\
\text { (2018) }\end{array}$ & $\begin{array}{l}\text { Este trabalho tem como tema o perfil dos docentes que atuam nos cursos de } \\
\text { Secretariado Executivo na Região Sul do Brasil (Rio Grande do Sul, Santa } \\
\text { Catarina e Paraná). A pesquisa justifica-se pelo fato de não haver muitas } \\
\text { publicações e pesquisas sobre a temática e por contribuir com a discussão acerca } \\
\text { da docência como uma possibilidade de atuação profissional. O objetivo principal é } \\
\text { identificar o perfil dos docentes, a fim de destacar os seus campos de atuação na } \\
\text { educação superior e as competências necessárias para exercer a profissão. } \\
\text { Metodologicamente, realizou-se uma revisão bibliográfica e aplicou-se um } \\
\text { questionário para a coleta de dados. Dos } 19 \text { questionários enviados, apenas } 9 \text { foram } \\
\text { respondidos. Por meio da análise dos perfis coletados, foi possível perceber que } \\
\text { além de atuarem como docentes, praticam atividades extras nas áreas de gestão, } \\
\text { pesquisa e extensão na instituição em que trabalham. Todos apontaram a } \\
\text { necessidade de buscar formação complementar ao ingressar na carreira docente, e } \\
\text { as competências que julgam mais importantes para a docência são a ética, a } \\
\text { inovação, o domínio de conteúdo e o domínio didático. }\end{array}$ \\
\hline
\end{tabular}

Quadro 1: Estudos Empíricos relacionados à docência em Secretariado.

Fonte: elaboração própria, com base nos trabalhos publicados.

A partir dos estudos acima, indica-se uma variabilidade de estudos científicos que já discutem a docência no secretariado, como: a relevância da monitoria para a graduação, os secretários-docentes, a inserção do docente secretário em programas de pós-graduação, a formação didático-pedagógica dos bacharéis em secretariado executivo.

Em se tratando da precípua necessidade de um ensino e aprendizagem, em um sentido mais amplo, deve-se evitar uma educação compartimentada, composta por ementas estanques e atividades padronizadas, tais estratégias de ensino precisam ser consideradas pelo professor. Além disso, é importante destacar que a contextualização não é restrita à vinculação com o cotidiano, embora essa seja a sua forma mais comum. 
Segundo a BNCC (Brasil, 2017), a contextualização proporciona a compreensão autêntica dos saberes, deixando de lado os métodos mecanicistas para a interpretação de problemas reais que envolvam o conteúdo estudado. É nesse novelo que surge a imperiosa contribuição do SE e sua atuação técnico-profissional. Ele tem a possibilidade de compartilhar com os alunos ricas e sólidas experiência relacionadas à área. Tais experiências são mais bem compreendidas por permitirem aos acadêmicos vislumbrarem e/ou reportarem-se para o futuro profissionais que poderão ser.

\section{Procedimentos Metodológicos}

Para os efeitos deste trabalho, como a pesquisa ocorreu em um contexto específico, a natureza é básica. Para Gerhardt \& Silveira (2009), a pesquisa básica tem o intento de gerar conhecimentos novos sem aplicação prática prevista, com utilidade para o avanço da ciência.

No que se refere à abordagem, a pesquisa é de abordagem predominantemente qualitativa. Em relação aos objetivos, do tipo exploratória e descritiva. O caráter exploratório desta pesquisa caracteriza-se por trabalhar com um universo de significações, motivos, aspirações, atitudes, crenças e valores. "Esse conjunto de dados considerados qualitativos" corresponde a um espaço de fenômenos à operacionalização de variáveis (Minayo, 2004, p. 28). A pesquisa também foi descritiva, pois descreveu as características de determinada população e fenômeno (Gerhardt \& Silveira, 2009).

$\mathrm{O}$ universo é composto por profissionais que atuam ao mesmo tempo como SE e docente, sendo desconhecido, por não ter nenhuma base ampla de dados sobre esse perfil. A partir de contatos realizados pelas mídias sociais, e-mail e por meio de um levantamento de associados efetivos e fundadores junto à Associação Brasileira de Pesquisa em Secretariado (ABPSEC), constante no site https://abpsec.com.br/associados/, foi possível chegar a uma amostra de 11 pessoas que responderam ao questionário proposto, das quais cinco são filiadas à ABPSEC, sendo essa amostra caracterizada como não probabilística por conveniência e julgamentos (Nobre et al., 2016; Sabino, Rocha \& Souza, 2017). Ao todo, esse instrumento foi enviado para 21 pessoas.

Quanto aos procedimentos técnicos, foram realizadas pesquisas bibliográfica e documental, com base em artigos de periódicos, capítulos de livros e regulamentações legais como, as DCN do curso de Secretariado Executivo e a LDB, bem como pesquisa de campo, a partir da aplicação do método survey (Freitas, Oliveira, Saccol \& Moscarola, 2000). Acompanhando esse método, o instrumento da coleta de dados adotado foi o questionário 
que, segundo Gerhardt \& Silveira (2009), é uma ferramenta de perguntas abertas e fechadas que possui as seguintes vantagens: a) distribuição mais rápida com perguntas padronizadas, o que facilita a coleta de dados; b) atinge maior número de pessoas em modo simultâneo e c) propicia maior liberdade nas respostas, em razão do anonimato garantido.

O questionário foi desenvolvido na ferramenta Google Formulários, com em perguntas e respostas extraídas dos estudos acerca da docência em Secretariado expostos no Quadro 1. Tal questionário foi aplicado no mês de junho de 2019, por meio de e-mails coletados de contatos próximos, de levantamento junto à ABPSEC, além da coleta via aplicativo WhatsApp. O questionário conteve dois blocos. O primeiro bloco consistiu no levantamento dos seguintes dados pessoais e funcionais: a) idade; b) sexo; c) região onde mora; d) formação em nível superior; e) formação em nível de pós-graduação; f) se já fez alguma capacitação relacionada a didática/docência para o ensino superior.

A segunda parte do questionário foi balizada nas seguintes questões: a) atuação anterior ou atual como dupla jornada; b) motivos que levaram o profissional a ser docente; c) benefícios em atuar na dupla jornada; d) dificuldades de atuação; e) se o entrevistado/a enxerga semelhanças entre a atuação secretarial e docente; f) quais as diferenças/impactos entre as funções secretarial/administrativa e docente; g) se recebe ou recebeu feedback de discentes, assessoria pedagógica e coordenação de curso quanto à metodologia de ensino e aprendizagem; h) se os cursos de secretariado executivo contribuem, de algum modo, para a preparação à docência; i) demais comentários que considerar necessários.

A técnica de análise de dados foi a análise de conteúdo. Sobre ela, Bardin (2016) aponta as seguintes fases: pré-análise, em que se estabelece um contato inicial com as entrevistas em grupo e individuais; exploração do material, em que foram definidas as seguintes categorias de análise e descrição: a) dados pessoais e funcionais; b) dupla jornada: benefícios e dificuldades; c) dupla jornada: semelhanças diferenças e d) atuação profíssional na dupla jornada e panorama universitário, em que consistem nos julgamentos necessários para a devida análise. Para preservar as identidades dos respondentes, as identificações estão localizadas pela letra $\mathrm{R}$ (de respondente), acrescido da ordem numérica (exemplos: R1 a R11), de acordo com os retornos dos profissionais.

\section{Resultados e discussões}

\subsection{Dados Pessoais e Funcionais}


Inicialmente, informa-se que o questionário foi aplicado a 21 profissionais formados na área secretarial e que possuem experiência docente, com o retorno de 11 questionários respondidos, o que compreende um retorno de 52,39\% dos questionários enviados, considerados suficientes para a análise dos resultados seguintes e de acordo com a caracterização da amostra não probabilística por conveniência. No tocante à faixa etária, mais da metade $(63,6 \%)$ possui idade entre 30 a 35 anos. Adicionalmente, $63,6 \%$ dos entrevistados são mulheres e 36,4\% são homens.

A distribuição geográfica dos entrevistados é maior nas regiões Sudeste (5 respondentes - $45,5 \%$ do total) e Norte (3 respondentes - 27,3\% do total). Acerca da formação, foi perguntado se formado/a em bacharelado ou tecnólogo em Secretariado/Secretariado Executivo ou curso equivalente. 11 respondentes informaram que possuem graduação em Secretariado/Secretariado Executivo, enquanto uma respondente informou que possui formação como tecnólogo em Secretariado.

Também foi perguntado se o profissional fez ou faz algum curso (pós-graduação, aperfeiçoamento, capacitação e/ou educação continuada) relacionado à docência, metodologia de ensino e aprendizagem, didática no ensino superior. $63,6 \%$ dos respondentes afirmaram que sim, enquanto $36,4 \%$ responderam que não, conforme o Gráfico 1 :

6. Em complementação à questão anterior, você já fez ou faz algum curso (pós- graduação, aperfeiçoamento, capacitação e/ou educação conti...no e aprendizagem, didática no ensino superior? 11 respostas

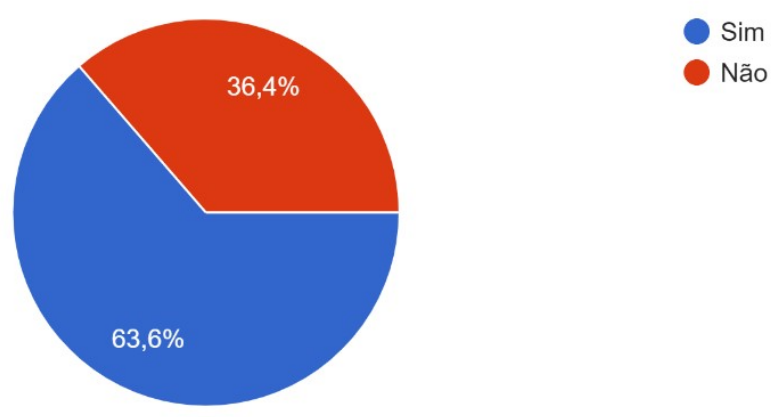

Gráfico 1: Panorama de realização de cursos de capacitação voltados à metodologia/didática/docência pelos secretários-docentes.

Fonte: dados da pesquisa.

Os resultados confirmam as proposições de Costa \& Porto (2016), que indicam a necessidade de complementação de saberes pedagógicos no exercício da docência secretarial, sendo de modo continuado e permanente. 
Em continuidade às perguntas, para os que informaram que fizeram (ou fazem) cursos relacionados à docência, metodologia de ensino e aprendizagem, didática no ensino superior, foi perguntado quais foram os cursos realizados, conforme dados do Quadro 2:

\begin{tabular}{|c|c|c|c|}
\hline $\begin{array}{l}\text { Identificação dos } \\
\text { Secretários }\end{array}$ & $\begin{array}{l}\text { Cursos concluídos e/ou em } \\
\text { andamento, com a respectiva } \\
\text { área de conhecimento: }\end{array}$ & $\begin{array}{l}\text { Se fizeram cursos } \\
\text { relacionados à } \\
\text { docência: }\end{array}$ & $\begin{array}{c}\text { Quais foram os cursos, caso } \\
\text { tenha feito: }\end{array}$ \\
\hline $\mathbf{R 2}$ & $\begin{array}{l}\text { Recursos humanos, metodologia } \\
\text { do ensino superior, gestão do } \\
\text { capital humano }\end{array}$ & Sim & $\begin{array}{l}\text { Metodologia do ensino } \\
\text { superior. }\end{array}$ \\
\hline R4 & $\begin{array}{l}\text { Especialista em Gestão de } \\
\text { Negócios e mestranda em } \\
\text { Educação Profissional e } \\
\text { Tecnológica }\end{array}$ & Sim & $\begin{array}{l}\text { Mestrado Profissional em } \\
\text { Educação Profissional e } \\
\text { Tecnológica }\end{array}$ \\
\hline R5 & $\begin{array}{c}\text { Administração com ênfases em } \\
\text { Finanças }\end{array}$ & Sim & $\begin{array}{c}\text { Pós-graduação em Assessoria } \\
\text { Executiva com um módulo } \\
\text { dedicado a metodologias de } \\
\text { ensino }\end{array}$ \\
\hline $\mathbf{R 7}$ & Gestão Pública & Sim & - \\
\hline $\mathbf{R 8}$ & Mestrado em Linguística & Sim & $\begin{array}{l}\text { Metodologia do ensino de } \\
\text { língua portuguesa e estrangeira }\end{array}$ \\
\hline $\mathbf{R 9}$ & Mestrado em Administração & Sim & $\begin{array}{c}\text { Formação para Docentes em } \\
\text { Ensino Superior }\end{array}$ \\
\hline R10 & $\begin{array}{c}\text { Especialização em Assessoria } \\
\text { Executiva e Mestrado em } \\
\text { Educação }\end{array}$ & Sim & $\begin{array}{c}\text { Estou cursando Especialização } \\
\text { em Docência no Ensino } \\
\text { Superior na } \\
\text { Contemporaneidade }\end{array}$ \\
\hline R11 & $\begin{array}{c}\text { Especialização em Ensino de } \\
\text { Francês Língua Estrangeira } \\
\text { (concluída - Ensino/Letras); } \\
\text { MBA em Assessoria Executiva } \\
\text { (concluído - Secretariado); MBA } \\
\text { em Gestão Estratégica de } \\
\text { Pessoas, Liderança e Coaching } \\
\text { (em andamento - } \\
\text { Administração). }\end{array}$ & Não & $\begin{array}{c}\text { Tenho Licenciatura em Letras, } \\
\text { mas nunca fiz curso voltado } \\
\text { para docência no ensino } \\
\text { superior. }\end{array}$ \\
\hline
\end{tabular}

Quadro 2: Cursos de capacitação/aperfeiçoamento de docência, metodologia de ensino e aprendizagem e didática no ensino superior realizados pelos secretários-docentes.

Fonte: dados da pesquisa.

Percebeu-se uma variedade de cursos relacionados e próprios à metodologia, didática de ensino e docência, o que reflete no esforço dos profissionais para a aplicação em sala de aula de recursos pedagógicos que facilitam o processo de ensino e aprendizagem (Silva, 
Barros \& Souza, 2010, Costa \& Porto, 2016, Sanches, Cielo \& Yaegashi, 2018). Essa informação vai ao encontro das interpretações de que a experiência profissional contextualizada e a constante atualização dos conhecimentos didático-pedagógicos são elementos combinados e necessários à atuação do SE enquanto docente.

\subsection{Dupla Jornada: benefícios e dificuldades}

O que toca o coração das pessoas move, faz com que elas se sensibilizem ampliando a visão de mundo, saiam do comodismo e passem a enxergar e compreender mais o outro e o que está no seu entorno, acontecendo assim à transformação das atitudes e dos valores de cada um. (Moriconi, 2014, p. 8).

O texto da autora acima reflete muito bem as informações adquiridas nesta pesquisa. Mais de 90\% dos profissionais com atuação em dupla jornada relataram, como benefícios da dupla jornada, a experiência, a ampliação dos conhecimentos, conforme relatos a seguir:

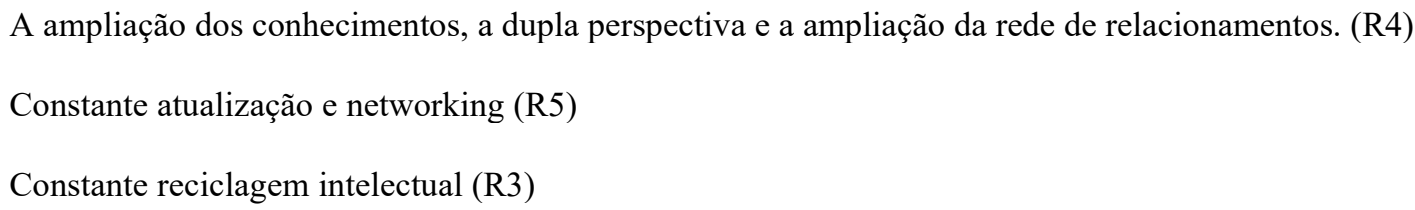

Tais relatos dialogam com os estudos de Winkel, Cassimiro \& Scachetti (2015), para os quais a dupla jornada promove um possível e necessário intercâmbio entre as práticas/atividades profissionais e acadêmicas. Para o docente/SE, a aproximação com a academia (retorno assumindo outro papel) o possibilita aperfeiçoar seus conhecimentos, compartilhar experiências, contribuir com pesquisa, ensino e extensão. Para o discente, é possível a formação de um novo perfil acadêmico e profissional, pois o SE/Docente consegue inserir no processo de ensino e aprendizagem a curiosidade, o espírito investigativo para a resolução de problemas reais. (Barros, Silva \& Barros, 2015).

Trata-se da adoção de uma cultura que possibilita a busca por respostas às inquietações dos acadêmicos, a partir da convivência com um profissional da própria área, o que reforça a questão da identificação com a profissão.

A BNCC (Brasil, 2017) orienta para a necessidade de se contextualizar os conteúdos segundo a realidade vivenciada pelos alunos, a fim de atribuir sentido e contribuir para uma aprendizagem significativa. Almeja-se por um processo de ensino e aprendizagem contextualizado, compreendido como a inserção do conhecimento disciplinar em uma realidade plena de vivências, buscando enraizar o conhecimento explícito na dimensão do conhecimento tácito. Mas como isso é possível? Esse enraizamento é possível por meio do aproveitamento e da incorporação de relações vivenciadas e valorizadas, tanto pelos 
SE/Docentes quanto pelos alunos, onde os significados se originam, ou seja, na trama de relações em que a realidade é tecida.

A contextualização, segundo o que preceitua a BNCC, é o meio pelo qual são enriquecidos os canais de comunicação, considerando a bagagem cultural, quase sempre essencialmente tácita, e as formas explícitas ou explicitáveis de manifestação do conhecimento na relação professor-aluno-escola-sociedade.

O R10 corrobora com esse tipo de ensino e aprendizagem, ao considerar como benefício da atuação paralela como: "A experiência é o principal benefício, pois atuar como secretária e ao mesmo tempo ser docente na área é enriquecedor. Um complementa o outro, ensino sobre o que aplico diariamente."

O R11, por sua vez, nos possibilita perceber que os ganhos não são apenas para os $\mathrm{SE} /$ Docentes, mas também para o aluno e a Instituição de ensino, pois esse processo de ensino e aprendizagem deve ser cíclico, com benefícios para todos: "Poder transmitir minhas experiências profissionais aos alunos.” Experiências e vivências que permitem ao graduando projetar-se para o futuro e vislumbrar uma carreira de sucesso.

Por outro lado, quanto às dificuldades encontradas pelo SE na atuação enquanto docente, dos 11 respondentes, um total de 6 foram enfáticos em considerar que a falta de tempo é um fator que dificulta a produtividade em sala de aula.

Não ter tempo suficiente para estudar, preparar aulas, planejar e executar didáticas de ensinoaprendizagem. (R1)

Tempo para executar as duas atividades, pois ambas exigem muito do profissional. (R6)

Tais relatos levam à constatação já muito discutida sobre a sobrecarga de trabalho com a docência, além da exigência de tempo para concentração e realização das tarefas docentes (Ávila Assunção \& Andrade Oliveira, 2009). Considerando a dupla jornada aqui discutida, a discussão possui uma outra dimensão, pois há a particularidade de o SE não possuir uma formação específica para atuação como docente. Logo, o que se percebe é que as experiências vivenciadas pelo profissional têm influência direta sobre a sua decisão de continuar ou não na profissão, porque este é um período marcado por sentimentos contraditórios, trabalhos intensos, tempo curto para a gama de responsabilidades atribuídas que desafiam cotidianamente o professor e sua prática docente.

Ainda quanto à dimensão dessa atuação paralela, a intensificação do trabalho $\mathrm{SE} /$ Docente, o corre-corre diário, o desrespeito aos horários biológicos de qualquer pessoa, noites mal dormidas, pressão para o cumprimento de metas, má alimentação, são um dos 
fatores que podem levar à fadiga crônica, ao stress. foi o que se constatou também nas respostas dos demais respondentes: "O estresse." (R2); “Acúmulo de funções" (R7); "Desgaste psicológico" (R8); "Cansaço" (R9), corroborando com os achados de Campos et al. (2008) e Lima \& Lima-Filho (2009) sobre as análises relativas às condições de trabalho do professor universitário, o que leva às reflexões acerca dos limites da atuação em dupla jornada.

\title{
4.3 Dupla Jornada: semelhanças e diferenças
}

Quando questionados sobre se enxergavam semelhanças entre a atuação secretarial e docente, os respondentes R1, R2 e R3 assim descreveram:

\begin{abstract}
Sim. Responsabilidade em cumprir o horário de trabalho, compromisso em aplicar os conhecimentos técnicos, zelo em fazer o melhor possível, assessorar o executivo e os alunos da melhor forma, entre outros. (R1)
\end{abstract}

Sim, a multidisciplinaridade, a necessidade de profissionalismo, inteligência emocional e gestão de informação e de pessoas, só que em ambiente acadêmico. (R2).

Sim, pois hoje o professor de qq área precisa ter s vivência prática (sic) (R3).

Santiago \& Silva (2017) compreendem, considerando o relato do R3, que o formador precisa ser dotado de experiência e conhecimento da área em que atua. A contextualização do conhecimento é o que preceitua a BNCC (Brasil, 2017). Trata-se de uma das técnicas/artifícios para conseguir reter a atenção dos alunos ao longo de uma aula. Ao invés de trabalhar o conteúdo pelo conteúdo, é interessante envolver os alunos nos acontecimentos do cotidiano, por exemplo, o SE pode explicar com propriedade como se assessora executivos em reuniões de negócios.

Infelizmente, a realidade das instituições de ensino ainda é marcada pela presença de uma grande maioria de docentes que não possui formação na área e que, mesmo assim, está à frente de disciplinas que demandam conhecimento de causa (Faria \& Reis, 2008). Esse fato devido à inexpressiva demanda, na área de secretariado, de profissionais que tenham interesse pela docência ou mesmo à falta de mais oportunidades de vagas em concursos públicos/processos seletivos (Santiago \& Silva, 2017).

Um dos pontos de convergência/semelhança, assim como em qualquer outra profissão, refere-se à necessidade de gerir o tempo, ter planejamento, organização e manter um bom relacionamento interpessoal, conforme relato do $\mathrm{R} 4$.

Sim. A capacidade de gerir o tempo, de organizar tarefas, articular projetos e relacionamento interpessoal. (R4). 
Competências que o SE já adquire/desenvolve durante a sua própria formação acadêmica, devido ao caráter interdisciplinar dos cursos que possuem um desenho curricular com disciplinas que dialogam entre si.

Quanto às diferenças/impactos entre as funções secretarial/administrativa e docente, o R4 enfatizou que a atuação docente é mais flexível, consegue-se uma melhor projeção e reconhecimento do que na atuação técnica de SE. O R10, por sua vez, complementa com a questão da autonomia que a docência possibilita.

Por outro lado, diferentemente da atuação enquanto SE, a função de docente cria uma sobrecarga maior de atividades, segundo o R11, pois a atuação não se restringe somente à sala de aula. De fato, a docência apesar da relativa flexibilidade, exige muito além do tempo dedicado em sala, requer planejamento das aulas, orientação de alunos, elaboração de provas, correção de trabalhos, pesquisa, extensão, atividades complementares. Atividades que extrapolam a carga horária exigida para o ensino e exigem concentração e retornos contínuos aos estudantes (Nossa, 1999).

\subsection{Dupla Jornada: atuação profissional e panorama universitário}

O(A) Secretariado(a) Executivo(a) de hoje é um profissional essencial, podemos considerar até indispensável para a gestão moderna, por reunir uma série de conhecimentos que a sua formação e a atuação diária o possibilitam: a difusão, organização e estratégias de atuação e gestão de pessoas e informações. Não se está falando mais daquele profissional executor de tarefas em nível operacional, mas daquele conhecedor/consciente de seu papel estratégico junto à gestão.

Contemporaneamente, esse profissional, ator organizacional, exerce o papel de gestor de informações. Ele possui visão abrangente da organização e estabelece suas ações a partir da definição de objetivos, prioridades; detêm conhecimentos sobre planejamento, organização, direção e controle, elementos presentes no campo da estratégia; constituindo a base de sua atuação (Rodrigues, Lavarda \& Martins, 2017). Trata-se de um novo perfil que reúne, além das competências de secretaria, a gerência, a assessoria, o trabalho com equipes e, mesmo, a gestão. É o que Schumacher \& Portela (2006) consideram como uma evolução. Para esses autores, o SE possui visão generalista, com técnicas, conhecimentos intelectuais, relacionais, sociais, políticos e de liderança. Seu diferencial está na sua capacidade de ser multifuncional, polivalente, inter e transdisciplinar, como enfatizam Müller, Stece \& Cegan (2015): 
A profissão de secretariado sofreu várias alterações no decorrer dos anos. Desde o surgimento da profissão até os dias atuais, a área secretarial se fortaleceu com o avanço no perfil profissional e nas atribuições de seus profissionais, que deixaram de ser meros reprodutores de técnicas para assumir postos cada vez mais complexos no ramo do secretariado, das assessorias e das inúmeras possibilidades de atuação dos secretários atuais (Müller, Stece \& Cegan, 2015, p. 133).

O contexto atual do "mercado de trabalho" vem remodelando o grau de interdependência entre as pessoas, consequentemente, novos riscos e incertezas surgem a reboque nas relações organizacionais (Andrade \& Garbelini, 2015). Nesse ambiente que Bauman (2001) considera como "modernidade líquida", remodela-se um novo perfil de SE, um profissional que busca novos desafios, a docência, por exemplo.

Esse novo perfil atribuído e desenvolvido pelo SE que, depois de formado, já atuando profissionalmente, decide voltar para a Universidade, mas, agora, assumindo um outro papel, o de docente. Esse fato pode ser constatado no questionário dos respondentes desta pesquisa: 63,6\% (7 pessoas) fizeram algum tipo de curso relacionado à docência, metodologia de ensino e aprendizagem, didática no ensino superior. Tal constatação dialoga com os estudos de Sanches, Cielo \& Yaegashi (2018), os quais consideram que o SE pode ser um "perito" em seu campo de atuação específica, mas demonstra lacunas na área pedagógica e educacional, quando se depara com a experiência da docência do ensino superior.

A busca por cursos que oportunizem a capacitação/qualificação em estratégias de ensino e aprendizagem demonstra que o SE, na função docente, possui mais do que o interesse por novas práticas, mas o compromisso com uma educação superior que favoreça o processo de conhecimento. Cajado, Barros \& Silva (2018), após análise dos dados sobre as contribuições do Programa de Iniciação à Docência da Universidade Federal do Ceará para o secretariado executivo, inferiram que tal programa colabora para o desenvolvimento de conhecimentos básicos necessários à docência na educação superior. Esse estudo corrobora com o percentual de mais de $50 \%$ dos entrevistados que responderam ter feito algum curso preparatório para a docência.

Em se tratando de ensino superior, o panorama é bem complexo pois, segundo Chauí (2003, p. 1), “A universidade é uma instituição social e como tal exprime de maneira determinada a estrutura e o modo de funcionamento da sociedade como um todo". Tal complexidade discutida sabiamente pela autora, devido ao remodelamento do papel da universidade como instituição e tornando-a uma organização operacional, regida por contratos de gestão, avaliada pelos índices de produtividade, calculada para “jogar” em tempo rápido profissionais para o mercado de trabalho. Vivemos a era das incertezas. 
Nessa era, com cortes danosos de recursos financeiros, há a extrema necessidade de revalorizar à docência, desprestigiada e negligenciada. Os dados coletados nessa pesquisa demonstram, no entanto, que mesmo com as dificuldades enfrentadas pelas instituições de ensino superior, os SE, então docentes, buscam novos conhecimentos para uma melhor atuação em sala de aula (90,9\% deles relatou que o motivo que os levaram à atuação enquanto docente deve-se à preocupação efetiva com a área). O compromisso com a educação permitenos entender que, segundo o educador Paulo Freire (2003), não significa simplesmente sair da condição de oprimido ou opressor, mas propor uma nova relação social, na qual haja igualdade entre homens e mulheres projetando um bem comum.

\section{Considerações Finais}

A área secretarial possui os seguintes pilares de atuação: assessoria, consultoria, gestão e empreendedorismo. Além disso, e mais recentemente, novas possibilidades de atuação têm emergido no contexto nacional, dentre eles, a experiência docente. Desse modo, o presente trabalho objetivou analisar benefícios, dificuldades, semelhanças e diferenças da dupla jornada como secretário executivo (SE) e docente.

Os resultados apontaram que a maior concentração do SE/Docente, para esta pesquisa, está nas regiões Sudeste e Norte; que o profissional possui bacharelado em secretariado executivo e preocupa-se em se capacitar continuamente para o exercício e aplicação de metodologias de ensino- aprendizagem nos cursos que ministra.

A pesquisa possibilitou, também, identificar os desafios e benefícios da atuação do profissional enquanto docente, em dupla-jornada. Os principais benefícios dizem respeito ao intercâmbio de conhecimentos, ampliação da rede de relacionamentos, atualização constante e transmissão de experiências profissionais. As dificuldades incluem a falta de tempo para aprofundamento nas atividades docentes, o desgaste psicológico, cansaço e acúmulo de funções, refletindo sobre os limites da atuação profissional, bem como na necessidade de ações institucionais que melhorem o ambiente de trabalho.

Por último, foram analisadas as semelhanças e as diferenças na vida profissional dos secretários-docentes. As principais semelhanças são a responsabilidade, o comprometimento, gestão da informação e de pessoas, inteligência emocional, gestão do tempo e relacionamento interpessoal. Entre as diferenças estão a flexibilidade na atuação docente, maior autonomia profissional na docência e divisão na carga-horária de trabalho, uma vez que a atuação administrativa demanda um tempo determinado no local de trabalho, enquanto a docência 
abrange atividades que demandam um tempo mais flexível, mesmo que não menos trabalhoso.

Algumas limitações foram observadas no decorrer da pesquisa: a) não há uma base de dados própria e acessível para consulta sobre os profissionais que foram ou são docentes, atuando em uma dupla-jornada (sendo esse um universo desconhecido); b) ainda que haja uma literatura em desenvolvimento, acerca na docência em secretariado, não foram encontrados trabalhos que abordem a questão da dupla-jornada na área, nem seus desdobramentos; c) impossibilidade de generalização de dados, tendo em vista o caráter qualitativo da pesquisa.

Desse modo, seguem sugestões para futuros estudos: a) estudos quantitativos de secretários-docentes que atuam em dupla-jornada; b) estudos regionais sobre a atuação de profissionais de secretariado em atuação administrativa e docente; c) estudos sobre a percepção dos estudantes acerca da atuação do SE enquanto docente.

\section{Referências}

Aili, C. \& Brante, G. (2007). Qualifying teacher work: everyday work as basis for the autonomy of the teaching profession. Teachers and Teaching: theory and practice, 13(3), p. 287-306.

Andrade, M. T. R. \& Garbelini, V. M. P. (2015). O profissional de secretariado e as competências demandadas pela responsabilidade social. Revista Organização Sistêmica, $7(4)$, p. 22-41.

Ávila Assunção, A. \& Andrade Oliveira, D. (2009). Intensificação do trabalho e saúde dos professores. Educação \& Sociedade, 30(107), p. 349-372.

Barbosa, M. A. C. \& Mendonça, J. R. C. O Professor-Gestor em Universidades Federais: alguns apontamentos e reflexões. (2014). Teoria e Prática em Administração, 4(2), p. 131-154.

Bardin, L. (2016). Análise de conteúdo. São Paulo: Edições 70.

Barros, C. M. P., Silva, J. S. da \& Lopes, D. M. (2014). A formação do secretário executivo que atua como professor universitário. Revista Capital Científico - Eletrônica (RCCe). 12(4), p. 62-77.

Barros, C. de M. P., Silva, J. S. da \& Barros, A. P. da C. H. (2016). Ensino com Pesquisa: Contribuições para a Cientificidade na Formação em Secretariado Executivo. Revista de Gestão e Secretariado, 7(1), p. 67-84. 
Bartlett, L. (2004). Expanding teacher work roles: a resource for retention or a recipe for overwork? Journal of Education Policy, 19(5), p. 565-582

Bauman, Z. (2001). Modernidade líquida. Tradução Plínio Dentzien. Rio de Janeiro: Jorge Zahar.

Brasil. (1989). Código de ética da profissão de secretariado executivo. Diário Oficial da União, 7 jun.

Brasil. (1996). Lei $\mathrm{n}^{\circ}$ 9.394, de 20 de dezembro de 1996. Lei de Diretrizes e Bases da Educação Nacional (Lei Darcy Ribeiro). Diário Oficial da União, Brasília, 23 de dezembro de 1996, Seção 1, p. 27833.

Brasil. (2005). Resolução n. ${ }^{\text {o }} 3$, de 23 de junho de 2005. Institui as diretrizes curriculares nacionais para o curso de graduação em Secretariado Executivo e dá outras providências. Diário Oficial da União, Brasília, 27 de junho de 2005, Seção 1, p. 79.

Brasil. (2017). Secretaria de Educação Básica. Base Nacional Comum Curricular. Ministério da Educação, Brasília, DF.

Cajado, T. da S., Barros, C. de M. P. \& Silva, J. S. da. (2018). Contribuições da monitoria em docência para a formação em secretariado executivo. Revista Expectativa, 17(2), p. 83106.

Campos, D. C. da S., Sousa, N. B. de, Campos, A. B., Cunha, N. R. da S., Magalhães, E. M. de \& Carvalho, R. M. M. A. (2008). Competências Gerenciais Necessárias aos Professores-Gerentes que Atuam em Pró-Reitorias: o caso de uma Instituição Federal de Ensino Superior de Minas Gerais. In: Encontro Nacional da Associação da Pesquisa e Pós-Graduação em Administração, 32, Rio de Janeiro. Anais eletrônicos. p. 1-16. Recuperado de: www.anpad.org.br/admin/pdf/GPR-A2302.pdf em: 23 abr. 2019.

Chauí, M. (2003). A universidade pública sob nova perspectiva. Rev. Bras. Educ., Rio de Janeiro, (24), p. 5-15.

Costa, I. E. \& Porto, B. de S. (2016). Formação didática de docentes de Secretariado Executivo nas instituições públicas de ensino superior no Brasil: um estudo observacional. In: Barros, C. de M. P., Silva, J. S. da \& Dias, A. M. I. (Org.). Secretariado Executivo e Educação: Temas que se articulam pela formação, docência na Educação Superior e pesquisa científica. Fortaleza: Edições UFC.

Faria, D. S. \& Reis, A. C. G. (2008). Docência em Secretariado Executivo. Fazu em Revista. Uberaba, (5), p. 169-174.

Freire, P. (2003). Educação e Atualidade Brasileira. 3. ed. São Paulo: Cortez; Instituto Paulo Freire. 
Freitas, H., Oliveira, M., Saccol, A. Z. \& Moscarola, J. (2000). O método de pesquisa survey. Revista de Administração, 35(3), p. 105-112.

Gerhardt, T. E. \& Silveira, D. T (Org). (2009). Métodos de pesquisa. Porto Alegre: Editora da UFRGS.

Lima, M. de F. E. M. \& Lima-Filho, D. de O. (2009). Condições de trabalho e saúde do/a professor/a universitário/a. Ciências \& Cognição, 14(3), p. 62-82.

Minayo, M. C. de S. (2004). O desafio do conhecimento: pesquisa qualitativa em saúde. 8. ed. São Paulo: HUCITEC.

Miranda, R. \& Tonieto, C. (2018). A docência no Secretariado Executivo na Região Sul do Brasil: traçando um perfil docente. Secretariado Executivo em Revist@, 14, p. 5-15.

Moriconi, L. V. (2014). Pertencimento e identidade. Campinas, SP: [s.n.].

Müller, R., Stece, V. \& Cegan, E. (2015). Perfil do (a) profissional de secretariado executivo na gestão contemporânea: evidências a partir dos ingressantes no mercado de trabalho na cidade de Curitiba, e das demandas empresariais. Revista de Gestão e Secretariado GeSec, 6(3), p. 129-151.

Nobre et al. (2016). A Amostragem na Pesquisa de Natureza Científica em um Campo Multiparadigmático: Peculiaridades do Método Qualitativo. In: Congresso IberoAmericano em Investigação Qualitativa, 5., Porto. Anais eletrônicos. p. 157-166. Recuperado de: https://proceedings.ciaiq.org/index.php/ciaiq2016/article/view/938 em: 30 nov. 2020.

Nóbrega, V. dos S. \& Adelino, F. J. da S. (2013). A inclusão do docente de secretariado executivo em programas de pós-graduação stricto sensu: um estudo realizado junto à plataforma Lattes do CNPq. Secretariado Executivo em Revist@, 8, p. 76-88.

Nossa, V. (1999). Formação do corpo docente dos cursos de graduação em Contabilidade no Brasil: uma análise crítica. Caderno de Estudos, (21), p. 1-20.

Oliveira, V. S. \& Silva, R. F. (2012). Ser bacharel e professor: dilemas na formação de docentes para a educação profissional e ensino superior. Holos, (2), p. 193-205.

Rasmussen, P. (2015). Professores inspiradores: como alguns educadores conseguem impactar nossas vidas mais do que podemos imaginar. 2015. Recuperado de: https://www.hypeness.com.br/2015/04/professores-inspiradores-como-algunseducadores-conseguem-impactar-nossas-vidas-mais-do-que-podemos-imaginar/ em: 17 jul. 2019. 
Rodrigues, L. M. A., Lavarda, R. A. B. \& Martins, C. B. (2017). O profissional de secretariado executivo: gestor de informações no processo de formação da estratégia. Revista Capital Científico - Eletrônica (RCCe), 15(3), p. 1-16.

Sabino, R. F., Rocha, F. G. \& Souza, E. C. P. (2017). A Geração Y no Secretariado: Análise Sobre a Carreira e suas âncoras. Revista de Gestão e Secretariado - GeSec, 8(3), p. 249272.

Sanches, F. C., Cielo, I. D. \& Yaegashi, S. F. R. (2018). Formação didático-pedagógica dos bacharéis docentes: uma análise nos cursos de secretariado das instituições públicas de ensino superior do Brasil. Revista Capital Científico - Eletrônica, 16(4), p. 86-104.

Santiago, C. da S. \& Silva, W. F. da. (2018). Secretários-docentes: sujeitos fundamentais à consolidação da docência secretarial. Secretariado Executivo em Revist@, 13, p. 143164.

Silva, J. S., Barros, C. M. P. \& Sousa, E. F. de. (2010). Docência em Secretariado Executivo: a valoração da experiência extraclasse. Revista Expectativa, Toledo, 9(9), p.43-60.

Vaz, C. de F. M. (2015). As experiências pedagógicas e a constituição do professor de secretariado executivo: narrativas de docentes. In: Encontro Nacional Acadêmico de Secretariado Executivo, 4., Londrina. Anais eletrônicos. p. 265-282. Recuperado de: https://abpsec.com.br/iv-enasec/anais/anais-do-iv-enasec-encontro-nacional-academicode-secretariado/ em: 21 jun. 2019.

Tavares, E. D., Alves, F. A., Garbin, L. S., Silvestre, M. L. C. \& Pacheco, R. D. (2007). Projeto de qualidade de vida: combate ao estresse do professor. Recuperado de: https://docplayer.com.br/11834444-Projeto-de-qualidade-de-vida-combate-ao-estressedo-professor.html em: 03 jun. 2020.

Winkel, S., Cassimiro, P. \& Scachetti, A. L. (2015). Professor de dia, gestor à noite: Atuação nas duas áreas colabora para que uma prática alimente a outra. Nova Escola, 286 Ed. Recuperado de: https://novaescola.org.br/conteudo/8495/professor-de-dia-gestor-a-noite em: 23 abr. 2019.

Submetido em: 07.10 .2020

Aceito em: $\quad 20.12 .2020$ 